\title{
Techno-Economics of a New High Throughput Process for Proton Exchange Membranes Manufacturing
}

\author{
Mathieu Toupin ${ }^{1}$, Kourosh Malek $^{2}$, Asmae Mokrini $^{1}$ \\ ${ }^{I}$ National Research Council Canada (AST), 75, de Mortagne Blvd. J4B 6Y4, Boucherville (QC), Canada \\ ${ }^{2}$ National Research Council Canada (EME), 650-1185 Georgia St W, V6E 4E6, Vancouver (BC), Canada
}

asmae.mokrini@cnrc-nrc.gc.ca

\begin{abstract}
Summary
NRC developed an innovative process for efficiently producing one of the PEMFC key components; the polymeric electrolyte. The process developed is based on the use of bifunctional additives and highthroughput melt-processing technologies. This work demonstrates the Techno-economic Cost Modeling (TCM) methodology to model the economics of production scale-up of NRC technology, and to analyze the feasibility of commercialization for different Fuel Cell Vehicles (FCV) annual production scenarios. Results were compared with the SOTA process used to manufacture e-PTFE reinforced composite perfluorosulfonic acid (PFSA) membranes based on solution-casting.
\end{abstract}

Keywords: Cost analysis, fuel cell, materials, proton exchange membrane,PEMFC.

\section{Introduction and Background}

Polymer Electrolyte Membrane Fuel cell (PEMFC) technology has been projected as the next revolution in clean energy generation, particularly for transportation applications. However, technical challenges such as cost and durability are still hindering their commercialization. There is a continuing need to reduce cost and the level of complexity while improving durability and reliability of the fuel cell system. The volumes associated with mainstream automotive manufacturing will bring into play beneficial economies of scale across the entire supply chain, leading to components of higher quality and lower cost. However, the automakers' approach to cost reduction is very aggressive as they seek total cost of ownership parity with internal combustion engine vehicles, [1] to gain the market-share required to have a positive environmental impact and reduce petroleum use.

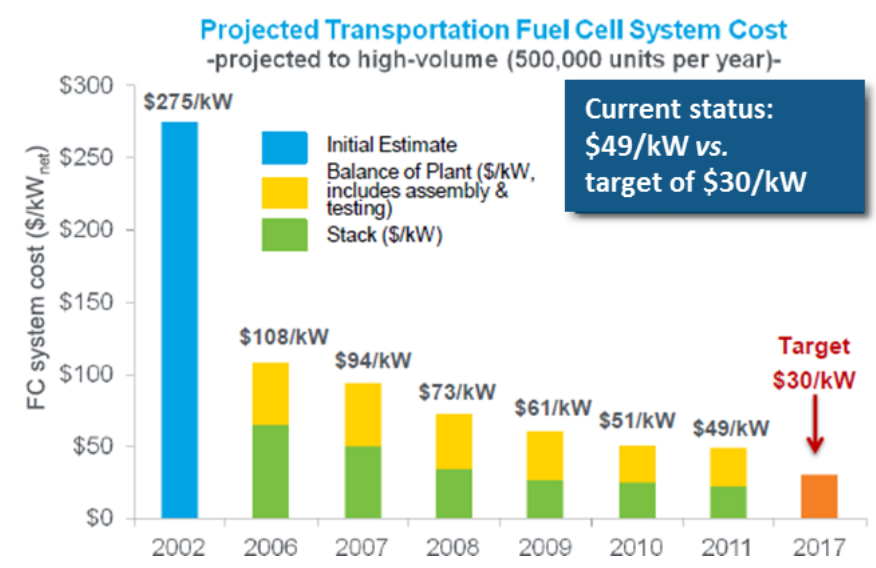

Figure 1. Modeled cost of an 80-kWnet PEM fuel cell system based on projection to high-volume manufacturing (500,000 units/year).[2] 
The Department of Energy (DOE) in the US has established detailed cost targets for automotive fuel cell systems and components. To help achieve these cost targets, the DOE has devoted research funding to analyse and track the cost of automotive fuel cell systems as progress is made in fuel cell technology. The cost analyses carried out by James et al. was to identify significant cost drivers so that R\&D resources can be most effectively allocated toward their reduction. The Polymer Electrolyte Membrane (PEM) was identified as one of the most expensive stack components and one needing to be reduced in cost to achieve a cost competitive fuel cell system, particularly for annual production rates (APR) below 80,000 Fuel Cell Vehicle FCV/year.[3]

\begin{tabular}{|c|c|c|c|c|c|}
\hline & \multicolumn{5}{|c|}{2015} \\
\hline Annual Production Rate & 1,000 & 30,000 & 80,000 & 130,000 & 500,000 \\
\hline System Net Electric Power (Output) & 80 & 80 & 80 & 80 & 80 \\
\hline System Gross Electric Power (Output) & 87.27 & 87.27 & 87.27 & 87.27 & $87.2 才$ \\
\hline Bipolar Plates (Stamped) & $\$ 1,634.29$ & $\$ 386.30$ & $\$ 392.11$ & $\$ 385.17$ & $\$ 380.72$ \\
\hline MEAs & & & & & \\
\hline Membranes & $\$ 4,657.35$ & $\$ 827.11$ & $\$ 507.81$ & $\$ 394.04$ & $\$ 204.21$ \\
\hline Catalyst Ink \& Application (NSTF) & $\$ 1,134.71$ & $\$ 578.48$ & $\$ 573.71$ & $\$ 572.51$ & $\$ 569.63$ \\
\hline GDLs & $\$ 1,853.85$ & $\$ 916.89$ & $\$ 565.27$ & $\$ 440.78$ & $\$ 196.86$ \\
\hline M \& E Hot Pressing & $\$ 71.29$ & $\$ 6.83$ & $\$ 6.54$ & $\$ 5.94$ & $\$ 5.95$ \\
\hline M \& E Curting \& Slitting & $\$ 56.55$ & $\$ 3.90$ & $\$ 2.76$ & $\$ 2.50$ & $\$ 2.19$ \\
\hline MEA Frame/Gaskets & $\$ 403.76$ & $\$ 263.06$ & $\$ 256.85$ & $\$ 253.61$ & $\$ 248.04$ \\
\hline Coolant Gaskets (Laser Welding) & $\$ 184.80$ & $\$ 26.26$ & $\$ 24.78$ & $\$ 24.44$ & $\$ 23.9 \mathrm{~d}$ \\
\hline End Gaskets (Screen Printing) & $\$ 149.48$ & $\$ 5.08$ & $\$ 1.97$ & $\$ 1.25$ & $\$ 0.53$ \\
\hline End Plates & $\$ 77.96$ & $\$ 27.02$ & $\$ 23.58$ & $\$ 21.51$ & $\$ 16.46$ \\
\hline Current Collectors & $\$ 15.08$ & $\$ 6.24$ & $\$ 5.16$ & $\$ 4.77$ & $\$ 4.36$ \\
\hline Compression Bands & $\$ 10.001$ & $\$ 8.001$ & $\$ 6.00$ & $\$ 5.50$ I & $\$ 5.00$ \\
\hline Stack Housing & $\$ 61.03$ & $\$ 7.13$ & $\$ 6.03$ & $\$ 5.46$ & $\$ 4.75$ \\
\hline Stack Assembly & $\$ 76.12$ & $\$ 40.69$ & $\$ 34.95$ & $\$ 33.62$ & $\$ 32.06$ \\
\hline Stack Conditioning & $\$ 166.06$ & $\$ 35.11$ & $\$ 27.72$ & $\$ 24.98$ & $\$ 16.84$ \\
\hline Total Stack Cost & $\$ 10,552.33$ & $\$ 3,138.09$ & $\$ 2,435.24$ & $\$ 2,176.09$ & $\$ 1,711.48$ \\
\hline Total Stack Cost $\left(\$ / \mathrm{kW}_{\text {net }}\right)$ & $\$ 131.90$ & $\$ 39.23$ & $\$ 30.44$ & $\$ 27.20$ & $\$ 21.39$ \\
\hline Total Stack Cost (\$\$/kW gross) & $\$ 120.91$ & $\$ 35.96$ & $\$ 27.90$ & $\$ 24.93$ & $\$ 19.61$ \\
\hline
\end{tabular}

Figure 2. Detailed PEM fuel cell stack cost for the 2015 technology system at different FCV Annual Production Rates (APR) [3]

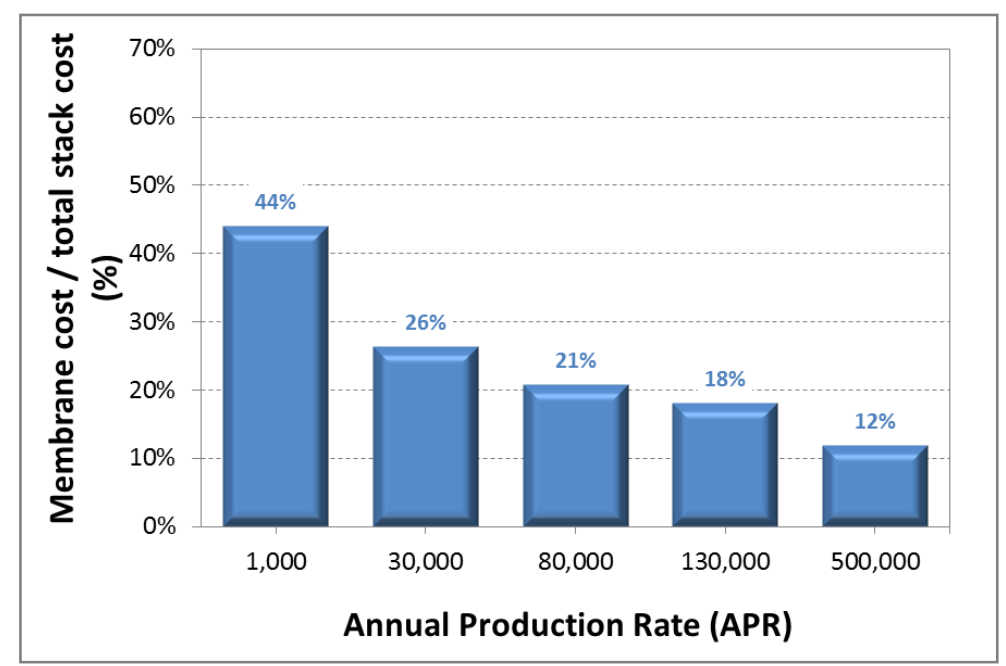

Figure 3. Membrane cost percentage as a function of FCV APR extracted from Figure 2

Perfluorinated sulfonic acid (PFSA) is the main membrane chemistry used in PEM fuel cells, several PFSA variants are commercially available such as Nafion $\AA$, Aquivion $\AA$, DOW $®$, Flemion®, etc. Most of fluoropolymers have a reduced performance and durability if operated for long periods of time at temperatures higher than about $80^{\circ} \mathrm{C}$. Over-hydration and excessive dehydration upsets the morphology of the fluoropolymers, and the resultant swelling or shrinking is undesirable and can lead to the formation of pinholes and fuel cell failure. Solution-cast Nafion ${ }^{\circledR}$ on a porous expanded polytetrafluoroethylene (ePTFE) substrate (Gore-Select® membrane) is the current state-of-the-art PEM for the automotive industry; 
e-PTFE support provides a solution to the mechanical durability, reaching the DOE target of 20,000 cycles according to US Fuel Cell Council protocols for automotive. Ionomer price greatly affects overall membrane cost and would drop by approximately $95 \%$ from low to high production volumes. However, the processing cost to manufacture the e-PTFE reinforced membrane remains a major, if not dominant, cost element. A process with a reduced number of steps and cost while maintaining the mechanical properties and the performance and durability of Gore ${ }^{\circledR}$ membranes, will certainly provide a cost competitive technology that meet the requirements for high volume commercial markets.

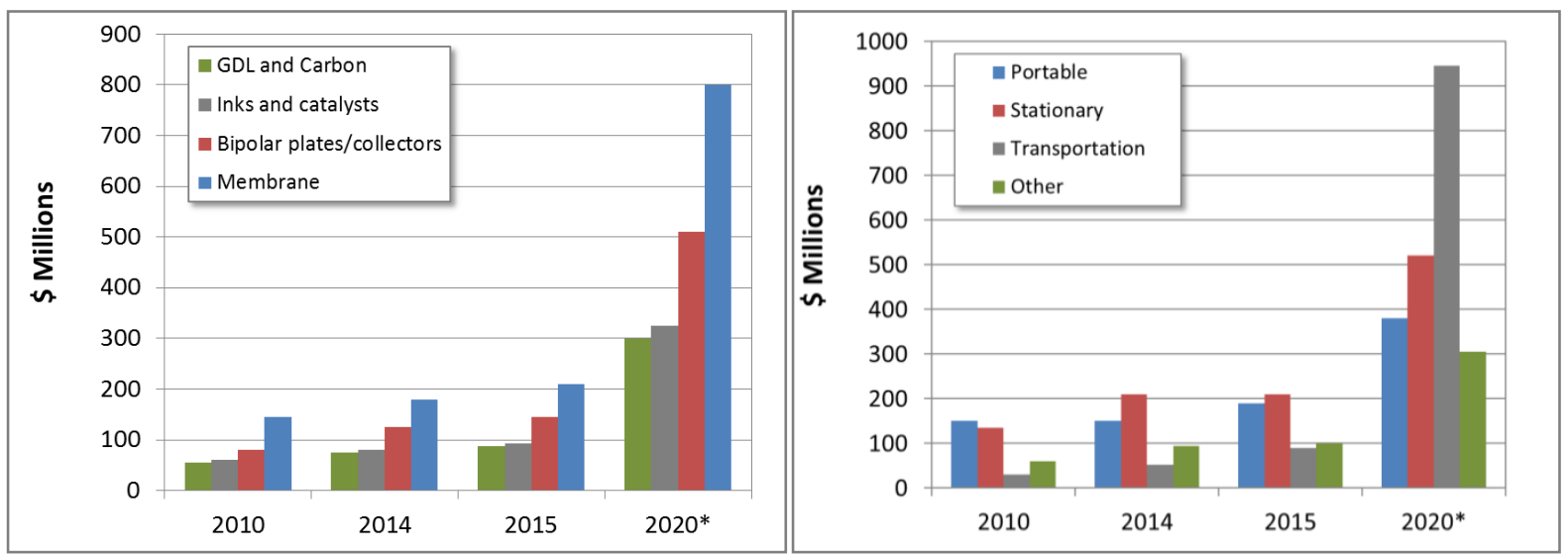

Figure 4. 2010-2015 Global PEMFC MEA market, and 2020 projection in M\$ [4]

BCC Research released a recent report with a comprehensive assessment of materials for protons exchange membranes and membrane electrode assemblies for PEM fuel cells.[4] The analysis focuses on the main components of the membrane electrode assembly (MEA) and applications for transportation but also stationary distributive power and small-scale applications such as portable electronic products. The report details the markets for every MEA component as well as PEMFC markets by application (Figure 4). The charts represent actuals for 2010 and 2014, forecasts for 2015, and projections for 2020 considering optimistic commercialization scenarios. The analysis shows a 209M\$ market for membranes in 2015, higher that all other MEA components and projects a 31\% annual growth (CAGR) between 2015 and 2020, with an $800 \mathrm{M} \$$ in 2020 . Also FC market for transportation is projected to be dominant in 2020 with a market of 945M\$.

\section{Objective, Scope and Approach}

The challenge for evaluating the economic feasibility of fuel cell materials and products is to relate materials properties that enable highest performance to costs associated with the materials fabrication process.[6] DOE/SA performed a process-based cost analysis for FC systems of $80 \mathrm{~kW}$ for automotive applications.[7] It predicted a combined auto fuel cell stack and system cost of $\$ 43$ to $\$ 52$ per $\mathrm{kW}$ for a production of 500,000 FCV systems/year on the basis of conventional materials and processes. A similar analysis for bus FC system with $160 \mathrm{~kW}$ power resulted in a cost estimate of $\$ 180$ to $\$ 233$ per $\mathrm{kW}$ for a production of 1,000 systems/year. James et al. has performed cost analyses for fuel cells for more than 10 years.[7] The analyses are based on complete automotive systems rather than focusing on the fuel cell power system. A novel process has been successfully developed and patented by NRC,[5] to produce polymer electrolyte membranes for PEMFC. The process developed is based on the use of bifunctional additives and high-throuput melt-processing technologies and can be readily scaled up for continuous highvolume manufacturing of proton exchange membranes, capable of meeting the demands of high volume production and durability requirements for automotive applications. The technology developed by NRC has demonstrated PEM with improved properties and durability higher than the DOE target; >20,000 cycle under automotive ADT protocols. This work intends to perform a comparative manufacturing cost analysis for NRC melt-extruded electrolyte vs. solution-cast reinforced electrolyte benchmark (e-PTFE-Nafion®). The main objectives are:

i) Quantify the cost reduction potential of the process developed at NRC compared to the benchmark, 
ii) Develop independent knowledge on technical-economical cost modeling that could be used to other components and systems, and

iii) Identify significant cost drivers to help further develop and commercialize this technology.

Cost modeling methodologies are typically used to estimate viability before a decision is made to employ a new production process or other product design changes. technical-economic cost modeling. (TCM) is a technique developed to model the economics of production scale-up of lab and pilot scale technology. TCM will be employed in the context of above mentioned membrane technology to provide cost and performance boundaries that assist in prioritizing current R\&D efforts and future investment, and to compare a new process, often still at the pilot or R\&D stage to benchmark processes along relevant parameters.

\section{Cost Modeling Background}

In a recent techno-economic cost study, two scenarios of cost analysis have been performed based on inputs and assumptions from DOE report [7], independent supplier estimates, new research approaches, and current market assumptions. The first scenario is assuming a modified membrane based on Nafion ${ }^{\circledR}$ with additive and produced using the Gore process and the second scenario is the Nafion ${ }^{\circledR}$ XL using the batch production with educated assumptions. These two scenarios cover the majority of possible production of membranes with durability and efficiency. Taleb et al.[8] found that the materials cost dominates the overall cost for both scenarios and that gore production process is more applicable for large membranes production. The TCM methodology was claimed to be correlated to the overall membrane industry by using the manufacturing process. Assuming material cost as a dominant factor, if the material changes, then the cost will automatically be reduced since the cost trend follows the material cost.

The costing methodology is inspired from the Design for Manufacture and Assembly technique (DFMA) introduced by Boothroyd. It takes in consideration direct material costs, manufacturing costs, assembly costs, and markup. $[9,10]$ Material cost is generated either from historical values, quotations or market expert assumptions. The selected scenarios for production volume in terms of vehicles per year, are aligned with the US-DOE projections.[3] This was realized to compare the cost and to appreciate how steep is the economy of scale for both processes. The cost study is separated in categories: operational mode, variable cost, fixed cost and financial cost. The later are detailed later. Assumptions for most of the parameters are based on budgetary quotations, when the latter were not available (i.e. ionomer \& e-PTFE) estimations were either based on the US-DOE study or estimated based on hands-on experience within NRC. The technological advantage of one versus the other was factored as equivalent, which is the best of the actual knowledge. The operational mode put forward here is based on the assumptions that the production line is dedicated to this particular PEM production which is the most stringent scenario where the fixed costs have the greater impact. A scenario for a large corporation that can batch this process on shared equipment would have considerable cost saving. The later was not chosen due to added complexity that is not necessarily relevant for this study.

\section{4 e-PTFE Solution Cast Process}

Perfluorosulfonic acid (PFSA), copolymers of tetrafluoroethylene and perfluorovinylether, are most widely used polymer membrane materials in the applications of proton change membrane (PEM) fuel cells in addition to chloralkali applications, due to their unique chemical/electrochemical stability, high mechanical strength, and high proton conductivity. They are commercialized under different trade names such as, Nafion (DuPont Co.), Aquivion (Solvay-Solexis), Aciplex (Asahi Chemical), Flemion (Asahi Glass), GoreSelect (W.L. Gore \& Associates). The bench mark membranes for PEM fuel cells are Nafion series.

The methods of manufacture processing of PFSA membranes are typically classified into two catalogues: melt-extruded and solution cast. The precursor of PFSA in its sulfonyl fluoride form melts above $200{ }^{\circ} \mathrm{C}$ and can be melt-extruded into membranes. Well-known PEMFC membranes from DuPont 10 years ago, Nafion 117, Nafion 115, and Nafion 112 are prepared through melt-extrusion process. In recent years, in order to lower the cost and improve fuel cell performance, membrane with the thickness $<30$ um has been demanded. Solution casting processing enables Nafion ${ }^{\circledR}$ membrane to be produced in thinner form (5-25 um). The typical membranes from DuPont from solution cast are: Nafion 212 and Nafion 211. In addition 
to the thickness, membranes from solution cast can easily incorporated with e-PTFE reinforcing materials and additives to enhance the durability of the membranes.

In 1994, Gore began to develop methods of incorporating proton-conducting ionomer into e-PTFE producing ionomer/e-PTFE composites with excellent mechanical strength. Because their properties of high fuel cell performance, longer life time and improved safety features even the membrane is damaged, currently, most PFSA membranes used in automotive fuel cell application are manufactured by solution cast reinforced by e-PTFE.

Even though being developed for tens of years, the detailed technology and parameters for producing PFSA membranes by Gore is still commercial confidential. Adopted from DOE report (James et al,DTI/DOE report, 2010) and some field experience of membrane fabrication, the procedure of preparing PFSA membranes by e-PTFE solution cast processing could be summarized as illustrated in Figure 5 .

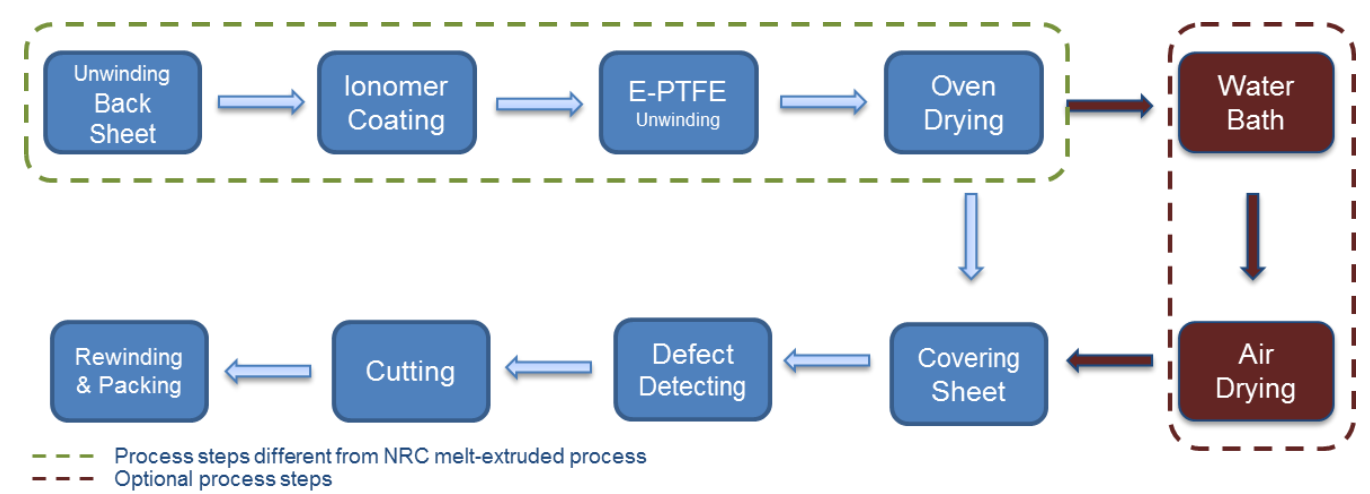

Figure 5. e-PTFE solution-cast membranes fabrication process steps

Briefly, the e-PTFE solution cast process could consist of primary eight (8) different steps. It starts by the unwinding of backing sheet as a base support of the cast line. The typical material for backing sheet is PET plastic. The PFSA ionomer is first casted on the backing sheet followed by covering e-PTFE sheet onto wet ionomer layer. The wet layer of ionomer and e-PTFE on backing sheet is then passing though the oven drying. To prevent the dust during the packing and transportation on membrane surface, the dried membranes usually covered a thin layer of covering sheet. After defect detecting on the sheets, the membrane is cut to required width before packing. The membrane should be tested for several properties and pass quality control before shipping.

Water washing and air drying steps are option for some special membranes with washable additives incorporated. However, it is worthy to mention that if the raw PFSA materials are not in acid dispersion form, two steps are necessary to add on before the steps in Figure 5 above. The sulfonyl fluoride group ($\mathrm{SO}_{2} \mathrm{~F}$ ) has be converted to sulfonic acid form by alkaline hydrolysis and subsequent acidification. The acid form ionomer solid should be dissolved in alcohol solvents and water at certain conditions. Since the membrane is only relatively thin (10-25 um), a few dust particle could cause pin holes and significantly reduce the lifetime of the membranes for automotive fuel cell applications. The e-PTFE solution cast membranes should be prepared in a clean room facility. The areas of ionomer coating and final covering steps are recommended to be operated in higher grade of clean room environment.

Sufficient heat and time are necessary to allow solvents evaporated, for PFSA ionomer to be tried, and to form the required morphology of the binary morphological networks (hydrophilic and hydrophobic) in the membranes during the oven drying step. Therefore, line speed is one of the crucial parameters and is identified as a limiting fact that affects the equipment efficiency and the product cost in the solution cast process. Usually, the oven size is 10-30 meter long considering the use of the space for the cast line equipment. The PFSA ionomer solution typically requires 10-30 minutes in the oven at the temperature controlled within $150-200{ }^{\circ} \mathrm{C}$ to become completely dry before covering another sheet on top. Therefore, the line speed of 0.3-3 meter/minute is recommended in the PFSA solution cast process. Practically, the line speed is controlled within $0.2-3 \mathrm{~m} / \mathrm{min}$. In the DOE report (James et al,DTI/DOE report, 2010), the dwell time crossing the ovens is 30 second might be not enough unless there has been some advanced technology adopted. 


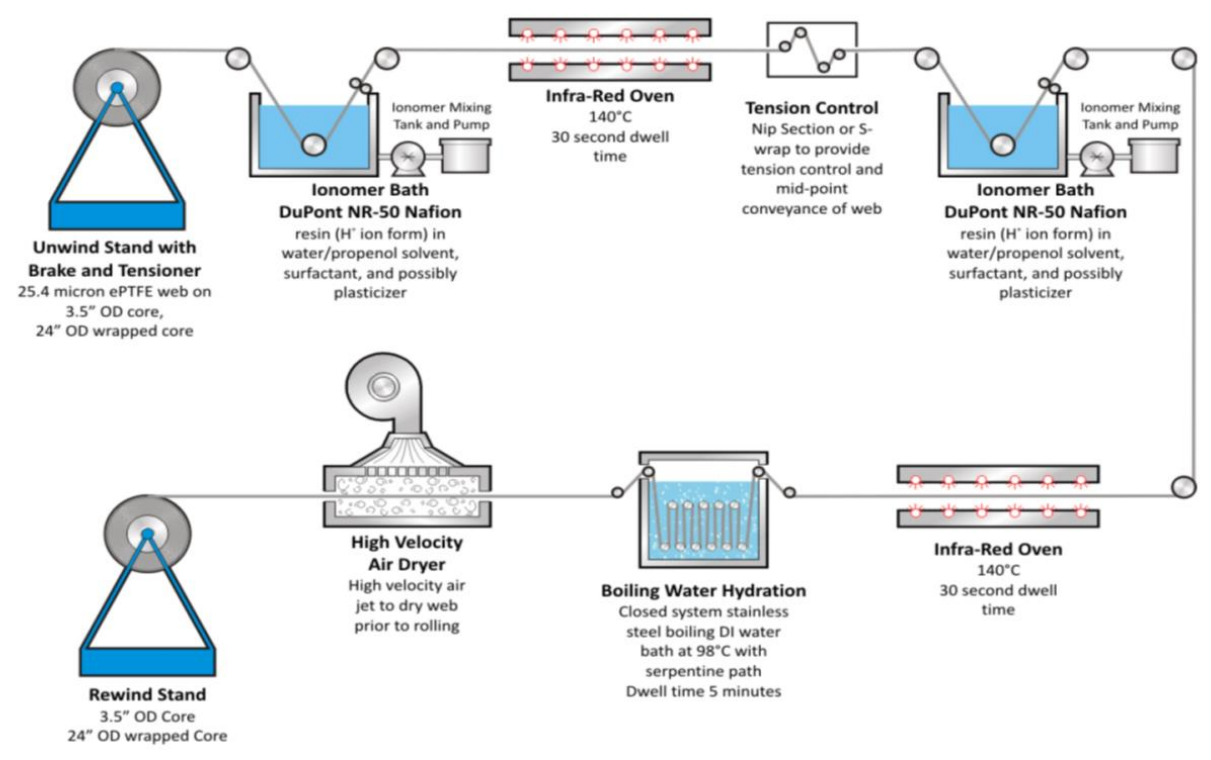

Figure 6. Gore e-PTFE supported Membrane fabrication process diagram from Ref [7]

\section{NRC Process}

National Research Council Canada in collaboration with its partners is actively working on the development of low cost manufacturing processes for advanced components. A novel process has been successfully developed and patented by NRC [5], that can be readily scaled up for continuous low cost mass production of solid polymer electrolytes, based on direct melt-extrusion of perfluorosulfonic acid (PFSA) ionomers in the acidic form. The technology developed is a unique, high-volume manufacturing process that produces low-cost, durable proton exchange membranes, capable of meeting the demands of high volume production and durability requirements for automotive applications.

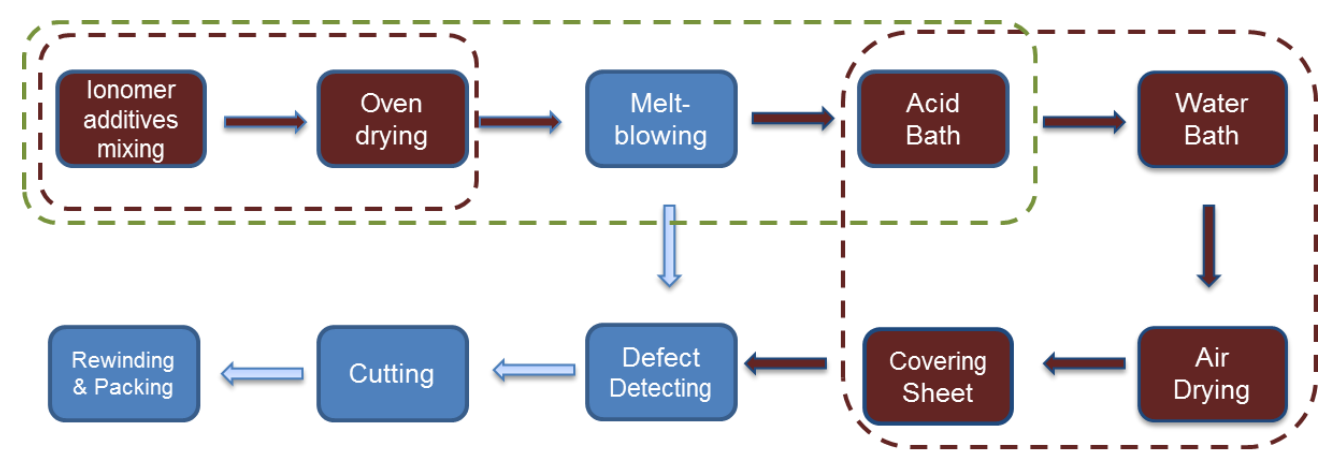

- - Process steps different from e-PTFE solvent-cast process

Figure 7. NRC melt-extruded membranes fabrication process steps

The process diagram for NRC melt-extruded membranes manufacturing illustrated in Figure 7, shows that the mains differences when compares to e-PTFE solvent-cast process, are mainly in the four first steps. The ionomer pellets in the acid form are first mixed with appropriate quantities of additive and solvent. Solvent used in this case is a mixture of ethanol and water, and the additive is from the azoles family such as triazole and benzimidazole. The concentration of additive and volume of solvent are calculated as a function of ionomer's ion exchange capacity (IEC). The pellets are afterward dried to totally remove solvent and fed to the multilayer melt-blowing line. The membranes obtained are washed with sulfuric acid and DI water to remove the additive. The washing steps might be optional if the additive can be easily removed during the fuel cell stack conditioning without compromising performance. The remaining steps are identical to e-PTFE solution-cast process, where the membranes are dried and protected with covering sheets to prevent surface contamination during packing and transportation. After quality control and defects detection, the membranes are cut to the width required by FC assembler before packing and shipping. 
Some advantages of NRC process is that blown film generally has a better balance of mechanical properties than cast or extruded films because it is drawn in both the transverse and machine directions. Mechanical properties of the thin film include tensile and flexural strength, and toughness. The nearly uniform properties in both directions (isotropy) allow for maximum toughness in the film, which translates in this case to PEMs with outstanding mechanical durability. It was demonstrated that membranes prepared with NRC process based on Nafion ${ }^{\circledR}$ NR-40 with an equivalent weight $E W=1000$, passed the 40,000 hydration dehydration cycles, compared to 23,000 cycles for e-PTFE reinforced membranes and 12,000 cycles for solution cast NRE-211. The chemical durability was also improved; cumulative fluoride loss (CFL) was more than one order of magnitude lower than Nafion ${ }^{\circledR} 211$ reference; $C F L=160 \mathrm{mmol} / \mathrm{cm}^{2}$ after 120 hours ( 9.6 cycles) for the stack with Nafion ${ }^{\circledR} 211$ baseline and $\mathrm{CFL}=5 \mathrm{mmol} / \mathrm{cm}^{2}$ after 162.5 hours $(13$ cycles) for the five cell stack with NRC PEM technology.

NRC process has been validated in a LabTech pilot-scale melt-blowing line available at NRC-Boucherville capable of running at a speed of $5 \mathrm{~m} / \mathrm{min}$ and providing $15-30 \mathrm{~cm}$ width membrane rolls. Brampton industrial scale melt-blowing line is also available at NRC-Boucherville and capable of producing $1 \mathrm{~m}$ large film, but was not used because of the large amounts of materials required to run it and the prohibitive cost of small volumes of PFSA ionomers.

\section{Comparative Cost Modelling}

\subsection{Operational Mode}

Fuel Cell Vehicle (FCV) production assumptions are based on the projection of the US-DOE[1] where 1000 FCV/yr would be the actual and 500000 FCV a high market penetration scenario. Polymer Electrolyte Membrane (PEM) area per stack was assumed at $10 \mathrm{~m}^{2} / \mathrm{FCV}$. To be able to sell a NET PEM volume, one has to produce a bigger quantity to account for the inevitable scraps. Scrap rate (\%) is assumed to be $30 \%$ at low production volume to account for frequent start-stops and drops to $15 \%$ at high volume, where losses are essentially associated with slitting of the membrane to the final shape required by the FC manufacturers. Combined to the operational mode assumptions and manufacturing equipment, output the running hours needed to meet these production volumes can be computed. Downtime is needed for cleaning of the equipment, preventive maintenance and occasional breakdown and was added as $15 \%$ of the total working hours. The utilization rate represents the fraction of the total potential usage of the manufacturing line. Reaching $100 \%$ means that the process runs 24/7 365 days a year and is generally considered an advantage that lowers the negative impact of the fixed costs.

The melt-blowing process is well known for its high throughput up to $100 \mathrm{~m} / \mathrm{min}$ when full scale equipment is used. Experiments using a pilot scale extruder proved that high quality films could be fabricated at $5 \mathrm{~m} / \mathrm{min}$. A small scale equipment with a lay flat of $0.8 \mathrm{~m}$ was sufficient to meet the demands up to 130000 FCV per year. For the 500000 FCV scenario a full scale equipment with a lay flat of $2 \mathrm{~m}$ was assumed and the production speed was increased to $6.4 \mathrm{~m} / \mathrm{min}$, which does not represent a serious quality risk. The first observation made where one facility would suffice to supply the global PEM demands up to $500000 \mathrm{FCV}$, is a disruptive one. This high throughput is not entirely a positive aspect of this process since it drives a low loading factor up to $80000 \mathrm{FCV} / \mathrm{yr}(0.7 \%$ to $55 \%)$ that puts a lot of pressure on the fixed cost and labor attrition. On the other hand, this helps in minimizing the labor and equipment costs.

The capacity of the solution-cast process is much lower than the melt-blowing process and reaches a full loading factor as soon as $5000 \mathrm{FCV} / \mathrm{yr}$. Moreover, as soon as $30000 \mathrm{FCV} / \mathrm{yr}$ multiple production lines have to run in parallel to meet the demand. This indicates that the equipment cost will be detrimental to this process and the cost in labor could be high. The full loading factor does on the other hand suggest that the value of this manufacturing plant will be used to its full potential and should have the most stable process.

When comparing the operational mode of both processes a quick analysis does bring out that the Meltblowing process will require less equipment and labor but will stay in a batch process mode for a long time. The drawback of this scenario is that a process that does not run in a continuous manner tends to be less stable generating more waste and client complaints. The solution cast, already well established could have an edge on that perspective and could stay the front runner if the cost advantage of the melt-blowing is not dramatic. On the other hand, for the melt-blowing process to gain this stability, usually resulting from the 
pool of know-how of retained qualified labour, this process should be introduced in an existing business which uses melt-blowing extruders.

\subsection{Variable Costs}

The variable costs include the labor, raw materials and the energy relative to the production volume, and will be detailed in the following sections.

\subsubsection{Labor Costs}

The direct labor cost is derived from the total working hours for the work force which is the sum of the running hours and the downtime as established by the chosen operational mode. The wage is estimated at $20 \$ / \mathrm{hr}$ taken from the US average for highly qualified labour [12] and the labor burden was chosen to be at $100 \%$ [11]. In both cases the direct labour was broken down in these categories: operator, rover, supervisor, 1 technical support. The melt-blowing process direct labour was estimated at 7 headcount per working hours across all production scenarios. The same estimate for e-PTFE solution cast shows that 12 to 70 employees are needed to carry out the work from low to high production scenarios. The observation that the solution cast process is much more labour intensive than melt-blown extrusion is in direct correlation with the operational mode described above.

The indirect labour accounts for the health and safety representatives, the environmental engineer, the sales representatives and management. The headcount for this category is fractional since these tasks can be contracted or shared between various activities within an organisation. This work force works only on the weekdays shift and decrease with a higher utilization rate which brings to opportunity to spread their workload on a longer period. The wage was estimated in the same way as for the direct labor. The bonuses generally associated with the sales and management positions are taken into account in the mark-up that will be applied to the net cost of the PEM and will be described later. Both processes use the same assumptions where a headcount of 5 indirect labours per working hour was attributed to low volume scenarios and the latter dropped down to 2 headcounts at high volume scenarios.

\subsubsection{Raw Materials, Consumables and Energy}

The ionomer considered here is Nafion NR-40 from Dupont for which the price was projected in the USDOE study according the trend showed in figure 1. Dupont was contacted to obtain quotes for various quantities of ionomers but provided limited information where orders $>500 \mathrm{~kg}$ are priced at $2780 \mathrm{USD} / \mathrm{kg}$. It is common for such high value goods that pricing are bound by contracts and high confidentiality. The provided figure was assumed in the NRC study for the $1000 \mathrm{FCV} / \mathrm{yr}$ scenario which falls into the order of magnitude of $500 \mathrm{~kg}$ of ionomer to satisfy the demand. All other scenarios were based on the US-DOE assumptions, which are qualified as aggressive. The melt-blowing process requires that an additive be added to the ionomer pellets prior to the extrusion which is accomplished by swelling the latter in a solution of additive in a mixture of ethanol-water. The quotations for the price of ethanol and additive (i.e. triazole) were obtained from established suppliers (Les Alcools de commerces Inc. \& Sigma-Aldrich) and are considered reliable. The e-PTFE solution cast process uses the same ionomer as previously described, the solvent is the same but the volumes needed for the solution cast are greater. The additives are nanoparticles of $\mathrm{CeO}_{2}$ that acts as radical scavenger. This product is tailor made for this particular application and the cost was assumed higher to what is advertised by well-known fine chemicals suppliers.

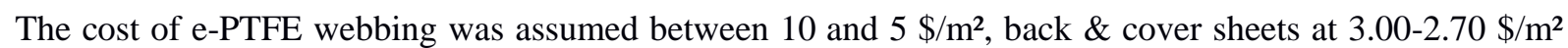
and packing at $0.2 \$ / \mathrm{m}^{2}$ for both process. Tooling accounts for parts of the equipment in direct contact with the product and wearing out due to normal use, i.e. the extrusion die. The latter generally must be replaced every $2 \mathrm{M}$ linear feet of extruded membrane and costs about $1.25 \mathrm{M} \$$ with added contingency for a full scale extruders and $35 \mathrm{k} \$$ for the small scale. This cost was fractioned to the production volumes accordingly.

The variable electricity cost is simply assumed as $80 \%$ of the available power of the equipment's main circuit multiplied by the running hours. Such type of equipment typically is hooked up to a $600 \mathrm{~V}, 200$ Amps circuit $(120 \mathrm{~kW} \mathrm{X} \mathrm{80 \%} 100 \mathrm{~kW})$. A second circuit was added to account for the peripheral 
processes for a total consumption estimated at $200 \mathrm{~kW} / \mathrm{h}$. The price per $\mathrm{kWh}$ is based on the average commercial rate for the US.[13]

\subsection{Fixed Costs}

The fixed costs are typically representative of the expense non-related to the production volume such as capital investments for equipment and expenses related to the building tenure. Each process was broken down into sub-categories considering the equipment, cleanroom depreciation costs and the building's maintenance, cleaning, utilities, administration, rent cost. For, the Melt-Blowing process the equipment cost was set between $1.8 \mathrm{M} \$$ for $1000-130000 \mathrm{FCV} / \mathrm{yr}$ and $5.6 \mathrm{M} \$$ for $500000 \mathrm{FCV} / \mathrm{yr}$. This includes the mixing reactor, dryers, extruders, film treatment and cleanroom costs. The solution cast process equipment cost includes relatively the same components and ramps up from 10.7 and $40.9 \mathrm{M} \$$ with volumes. The lifetime of this manufacturing line was put at 10 years. This allowed, using a straight line approach, to estimate the depreciation of the equipment. The Machine Yearly Cost is the depreciation on a yearly basis with an added $5 \%$ to account for the maintenance costs. The building costs were assumed based on US private sector averages for industrial floor space (e.g. rent, administration, utilities, cleaning, maintenance per $\mathrm{ft}^{2}$ ).

Figure 6 compares the fixed cost and it can be observed that the building cost contribution is similar for both processes. The main bias is driven by the equipment cost and is a great penalty to the solution cast process at production rate below $30000 \mathrm{FCV} / \mathrm{yr}$, for higher demand the fixed cost fades greatly to the point of being negligible.

\subsection{Financial Costs}

The production cost is the sum of the fixed and variable costs. To avoid getting into the details of the tax calculation altogether a mark-up that accounts for the income tax, profit, opportunity cost was applied to the production costs. In this case, "Profit" can be considered as a net of tax parameter. The mark up percentage was scale rated, decreasing profit margin as the production volume increases and as the tax bracket increases. A mark up of 100-150 \% at low volume and $~ 30-50 \%$ at high volume may be considered as a reasonable first estimate and it is susceptible to change greatly depending on the business structure (small vs large), geographical location (income tax) and structure of the company (public or private).This high level approach was chosen for this cost item to acknowledge the impact but is far from being a rigorous accounting exercise. The interest cost is calculated from the total equipment cost at an interest rate of $15 \%$ on a 10 years amortization period. The capital recovery is not included in this cost item; the depreciation described earlier accounts for that. The financial cost is the sum of the mark-up and interest costs.

\subsection{Cost Study Output and Conclusions}

Table 1. Comparison of projected total cost of polymer electrolyte membrane of melt-blowing versus e-PTFE solution-cast processes

\begin{tabular}{rllllll}
\hline Veh Production/yr & 1,000 & 5,000 & 30,000 & 80,000 & 130,000 & 500,000 \\
\hline Total yrly production $\left(\mathrm{m}^{2} / \mathrm{yr}\right)$ & 10,000 & 50,000 & 300,000 & 800,000 & $1,300,000$ & $5,000,000$ \\
Melt-Blowing cost $\left(\$ / \mathrm{m}^{2}\right)$ & $\mathbf{4 9 2 . 2 8}$ & $\mathbf{5 0 . 2 9}$ & $\mathbf{1 9 . 0 8}$ & $\mathbf{1 5 . 3 5}$ & $\mathbf{1 2 . 3 8}$ & $\mathbf{8 . 7 4}$ \\
e-PTFE Solution-Cast cost & $\mathbf{1 2 9 3 . 3 4}$ & 345.48 & 90.18 & 60.81 & 43.61 & $\mathbf{2 5 . 0 4}$ \\
$\left(\$ / \mathrm{m}^{2}\right)$ & & & & & & \\
Actual cost Nafion XL, & $\mathbf{1 6 0 0 - 2 3 0 0}$ & & & & & $\mathbf{1 8 . 1 8}$ \\
Nafion 211, Nafion HP & $\begin{array}{l}\text { (Ion Power } \\
\left(\$ / \mathrm{m}^{2}\right)\end{array}$ & Inc. $)$ & & & & $\mathbf{2 0 1 2 )}$ \\
\hline
\end{tabular}


Comparing in table 1 the price advertised by Ion Power Inc. representative of a low volume scenario and the one for a high volume scenario taken from the US-DOE study shows that the NRC methodology is able to predict relatively well the cost of today's PEM.

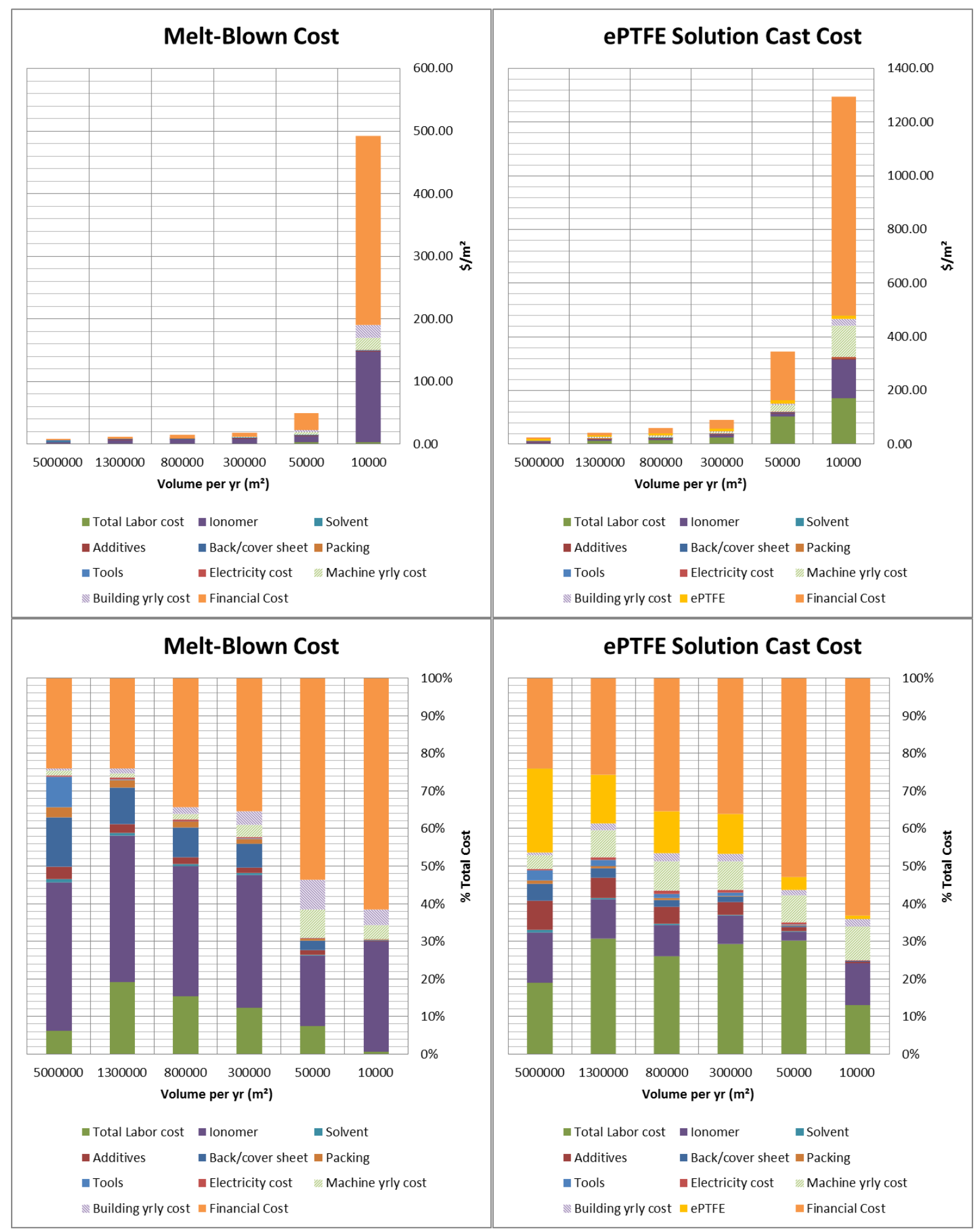

Figure 8. Breakdown of cost drivers for both processes 
Some key elements can explain the bias between the NRC and DOE cost study lies in the operational mode assumptions, a drastically lower ionomer cost at low volume (300 \$/kg for $1000 \mathrm{FCV}$ ) and the omission of the cost for the $\mathrm{CeO}_{2}$ additive which is not trivial. A global production of $1000 \mathrm{FCV}$ this year is realistic [15] meaning that the quoted price suggested by this study for the ionomer is reliable. When the high volume scenario is assumed parameters between the two studies are mostly equivalent beside one which is key and is somewhat problematic. The DOE cost study assumes a line speed of $35 \mathrm{~m} / \mathrm{min}$ which allow that a single production line be run to cover the required volumes of PEM. Such high speeds for a solution cast process are considered unrealistic by the NRC. Dupont patents US 7.648 .660 B2 suggests $3 \mathrm{~m} / \mathrm{min}$ to be the preferred line speed. To validate our methodology the assumptions for $500000 \mathrm{FCV} / \mathrm{yr}$ were changed to match the DOE study at: a scrap rate of $2 \%$ instead of $15 \%, 1$ manufacturing line instead of 4 , a workforce of 50 instead of 70 and omitted the cost for the $\mathrm{CeO}_{2}$ additive. The cost estimated by the NRC cost study drops to $17.72 \$ / \mathrm{m}^{2}$ which demonstrates that our approach is as valid as the DOE study and that the cost bias is related to the assumptions and not the computation methodology.

Figure 8 puts in perspective key cost drivers for both processes and allows drawing the following conclusions:

I. In all production scenarios the melt-blowing cost advantages is significant and at least a third of the e-PTFE solution cast (see table 1).

II. The cost of the solution cast process is driven by the labor, the e-PTFE and the financial cost. (Figure 8)

III. The cost of the Melt-Blowing process is driven by the ionomer, the financial and labor cost. (Figure 8)

The melt-blowing process technology develop by the NRC has a significant cost advantage for any kind of production scenario. The technological breakthrough of eliminating the need for the e-PTFE and $\mathrm{CeO}_{2}$ additive is far from trivial in the cost savings. The high throughput of the melt-blowing process lowers the labor cost and capital investments significantly ultimately lowering the financial risk. For PFSA based PEM the main cost driver remains the ionomer and any incremental reductions will have a significant impact.

\section{Acknowledgments}

Titichai Navessin from Pacific Rim Research and Alicia Maine from Simon Fraser University for consulting. Ken Shi from NRC-EME for discussions and recommendations, as well as Eric Baril and François Girard for their Support. Authors would also like to acknowledge NRC-AST for funding this project through NRC's Vehicle Propulsion Technology program.

\section{References}

[1] The Fuel Cell Today Industry Review (2013)

[2] US DOE FY 2013 Budget Request Rollout.February 14 (2012)

[3] B.D. James, J.M. Moton, and W.G. Colella, Mass Production Cost Estimation of Direct H2 PEM Fuel Cell Systems for Transportation Applications: 2013 Update (2014)

[4] D. Saxman. Materials for protons exchange membranes and membrane electrode assemblies for PEM fuel cells. BCC Research Sept (2015)

[5] Mokrini A. "PROCESS FOR PRODUCING ION EXCHANGE MEMBRANES BY MELT-PROCESSING OF ACIDIC PFSA IONOMERS" US patent US2014242368 (A1)

[6] Maine E., Ashby M., Succeeding with New Materials: A Comprehensive Guide for Assessing Market Potentia, Cambridge Publication

[7] Brian J.D.; Moton, Jennie M.; Colella, Whitney G.; "Mass Production Cost Estimation of Direct H2 PEM Fuel Cell Systems for Transportation Applications: 2013 Update”, Strategic Analysis Inc., DOE Award \# DEEE0005236.

[8] Taleb A., Maine E., Kjeang E., (2014),"Technical-economic cost modeling as a technology management tool", Journal of Manufacturing Technology Management, Vol. 25 Iss 2 pp. 279 - 298;

[9] Maine, E. a. (2000). Cost estimation and the viability of metal foams. Advanced Engineering Materials, Vol. 2, No. 4, , 205-209 
[10] Maine, E. a. (2002). Applying the investment methodology for materials (IMM) to Aluminum Foams. Materials and Design, Volume 23, Issue 3, 307-319

[11] https://en.wikipedia.org/wiki/Labor_burden

[12] US Bureau of Labor Statistics, http://www.bls.gov/oes/current/naics4_326100.htm

[13] http://www.eia.gov/electricity/monthly/epm_table_grapher.cfm?t=epmt_5_6_a

[14] Prajyot Sathe, Edward Hanawalt, Strategic Analysis of the Fuel Cell Vehicles (FCV) Market in North America and Europe, Frost \& Sullivan June 2014.

\section{Authors}

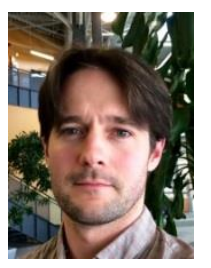

Mathieu Toupin obtained a Ph.D. in electrochemistry at Institut National de la Recherche Scientifique (INRS, Varennes, Qc, Canada) in 2007. He has since worked for IBM in the microelectronic division and now is a Research Officer at NRC working on various themes linked to the energy storage for electric vehicles.

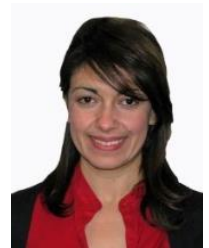

Asmae Mokrini obtained a master's degree in Polymer Science and T echnology form the university of Menendez Pelayo in Madrid-Spain, and a $\mathrm{PhD}$ in Chemical Engineering from the University of Barcelona in 1998. She is a Senior Research Officer at the National Research Council of Canada where she spent the last 13 years working on solid polymer electrolytes for electrochemical energy storage and generation devices for automotive applications, as well as process development to reduce components manufacturing cost. 